$1-1-2021$

\title{
Assessment of community-based ART service model linking female sex workers to HIV care and treatment in Blantyre and Mangochi, Malawi
}

\author{
Lung Vu \\ Population Council \\ Brady Zieman \\ Population Council \\ Adamson Muula \\ Vincent Samuel \\ Lyson Tenthani \\ Population Council
}

See next page for additional authors

Follow this and additional works at: https://knowledgecommons.popcouncil.org/departments_sbsr-hiv

Part of the Public Health Commons

How does access to this work benefit you? Let us know!

\section{Recommended Citation}

Vu, Lung, Brady Zieman, Adamson Muula, Vincent Samuel, Lyson Tenthani, David Chilongozi, Simon Sikwese, Grace Kumwenda, and Scott Geibel. 2021. "Assessment of community-based ART service model linking female sex workers to HIV care and treatment in Blantyre and Mangochi, Malawi," Project SOAR Final Report. Washington, DC: USAID | Project SOAR. 


\section{Authors}

Lung Vu, Brady Zieman, Adamson Muula, Vincent Samuel, Lyson Tenthani, David Chilongozi, Simon Sikwese, Grace Kumwenda, and Scott Geibel 


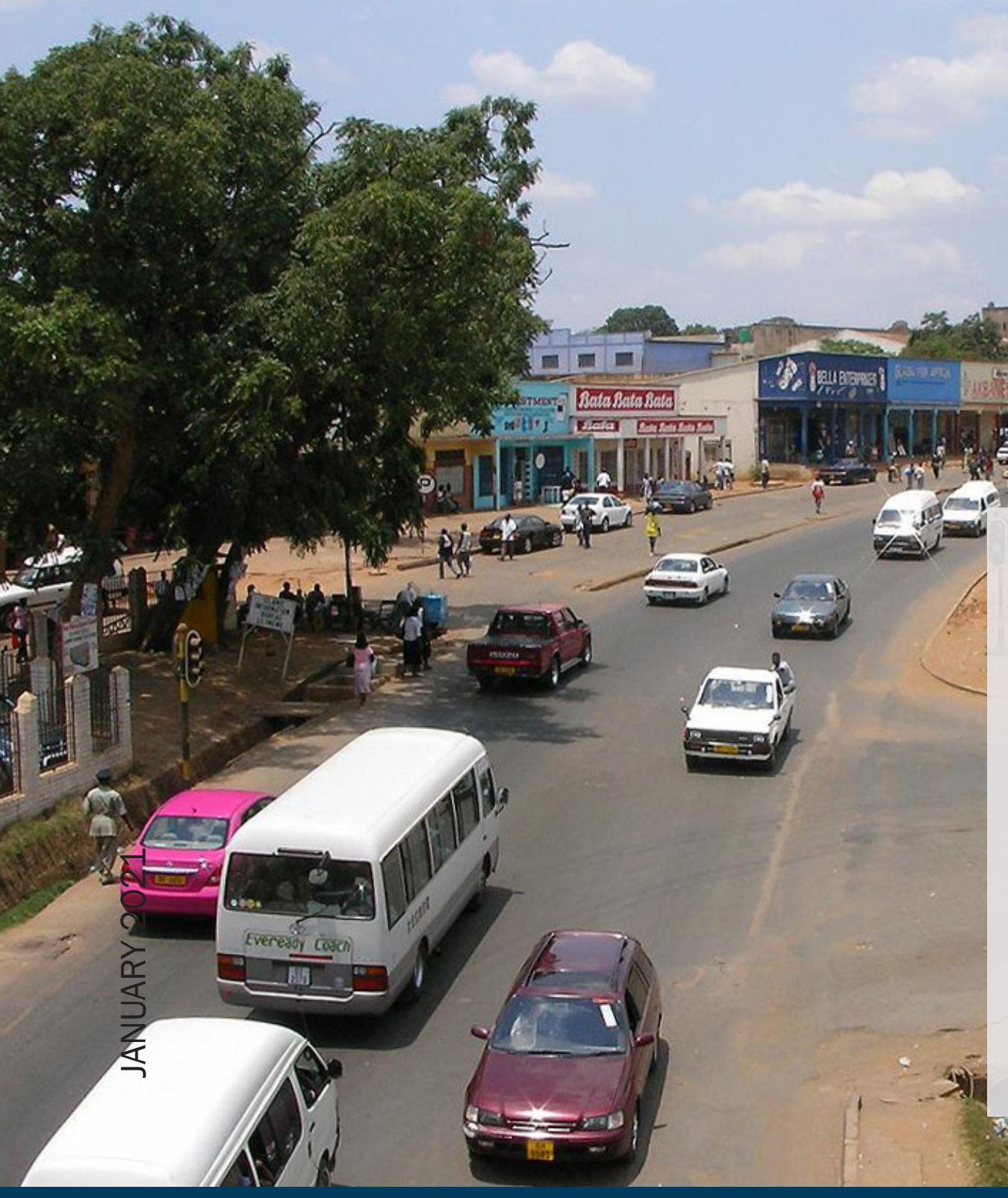


Project SOAR

Population Council

4301 Connecticut Ave, NW, Suite 280

Washington, D.C. 20008 USA

Tel: +1202 2379400

Fax: +1 2022378410

projsoar.org
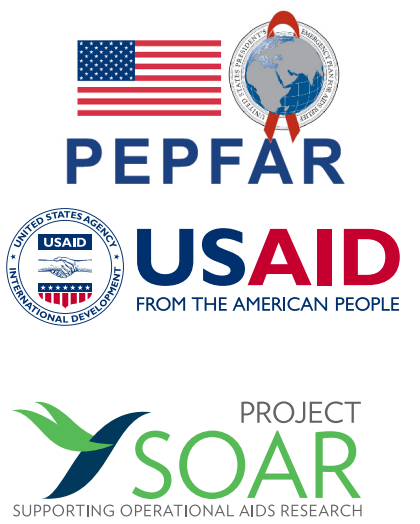

\section{- POPULATION COUNCIL}

Ideas. Evidence. Impact.
Project SOAR (Cooperative Agreement AID-OAA-A-14-00060) is made possible by the generous support of the American people through the United States President's Emergency Plan for AIDS Relief and the United States Agency for International Development (USAID). The contents of this report are the sole responsibility of Project SOAR and the Population Council and do not necessarily reflect the views of PEPFAR, USAID, or the United States Government.

Through operations research, Project SOAR will determine how best to address challenges and gaps that remain in the delivery of HIV and AIDS care and support, treatment, and prevention services. Project SOAR will produce a large, multifaceted body of high-quality evidence to guide the planning and implementation of HIV and AIDS programs and policies. Led by the Population Council, Project SOAR is implemented in collaboration with Avenir Health, Elizabeth Glaser Pediatric AIDS Foundation, Johns Hopkins University, Palladium, and The University of North Carolina.

The Population Council confronts critical health and development issues-from stopping the spread of HIV to improving reproductive health and ensuring that young people lead full and productive lives. Through biomedical, social science and public health research in about 50 countries, the Council works with our partners to deliver solutions that lead to more effective policies, programs, and technologies to improve lives worldwide. Established in 1952 and headquartered in New York, the Council is a nongovernmental, nonprofit organization with an international board of trustees.

Suggested citation: Vu, Lung, Brady Zieman, Adamson Muula, Vincent Samuel, Lyson Tenthani, David Chilongozi, Simon Sikwese, Grace Kumwenda, Scott Geibel. 2020. "Assessment of community-based ART service model linking female sex workers to HIV care and treatment in Blantyre and Mangochi, Malawi," Project SOAR Final Report. Washington, DC: USAID | Project SOAR. 


\section{Assessment of Community-based ART Service Model Linking Female Sex Workers to HIV Care and Treatment in Blantyre and Mangochi, Malawi}

Lung Vu, ${ }^{1}$ Brady Zieman, ${ }^{1}$ Adamson Muula, ${ }^{2}$ Vincent Samuel, ${ }^{2}$ Lyson Tenthani, ${ }^{1}$ David Chilongozi, ${ }^{3}$ Simon Sikwese,${ }^{4}$ Grace Kumwenda, ${ }^{4}$ Scott Geibel ${ }^{1}$

${ }^{1}$ Population Council, Washington, DC

${ }^{2}$ University of Malawi, College of Medicine, Malawi

${ }^{3} \mathrm{FHI}$ 360, Malawi

${ }^{4}$ Pakachere, Malawi

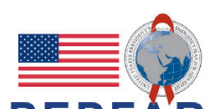

PEPFÂR
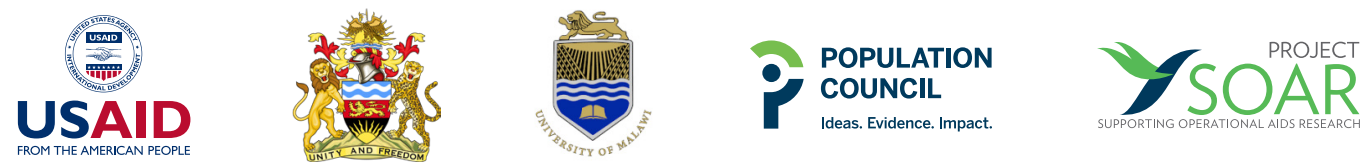


\section{ACKNOWLEDGMENTS}

We greatly appreciate the collaboration with our LINKAGES and Pakachere colleagues who implemented the study, especially the DIC clinicians, counselors, and peer educators who led the implementation of the pilot and provided critical support during two rounds of data collection. We would like to acknowledge the hard work of the field research coordinators Laura Moyo and Dukuma Kalua from College of Medicine, University of Malawi. This study would not be possible without the support of Ministry of Health, which provided support, recommendations, and government buy-in for this study. Lastly, we would like to thank the study participants for their willingness to participate and lead the way for the future of ART in Malawi. 


\section{TABLE OF CONTENTS}

ACKNOWLEDGMENTS..........................................................................................................

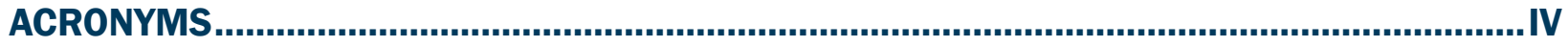

EXECUTIVE SUMMARY .............................................................................................................1

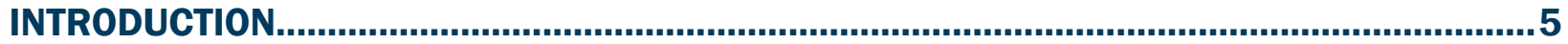

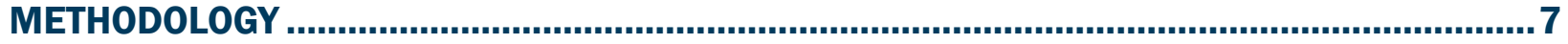

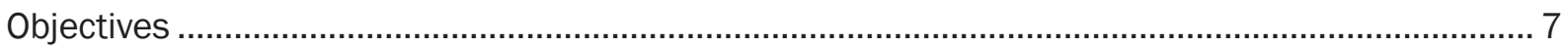

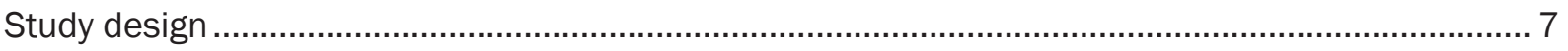

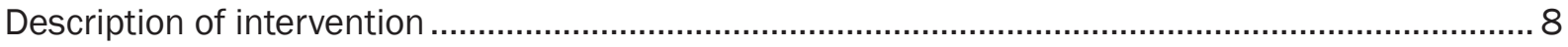

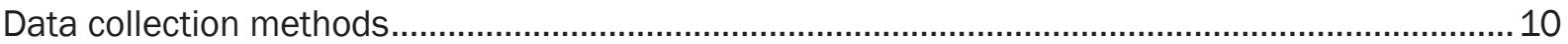

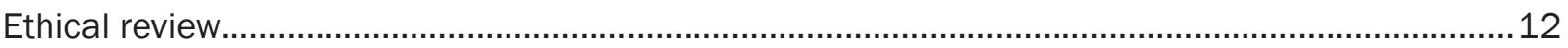

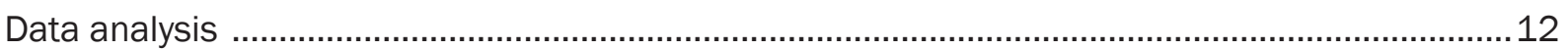

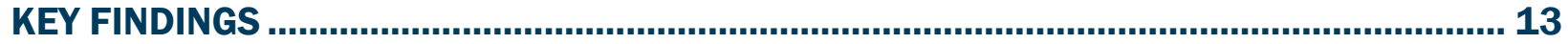

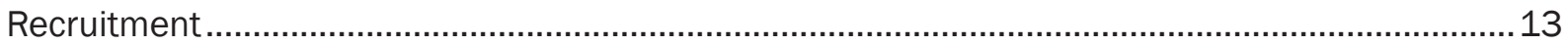

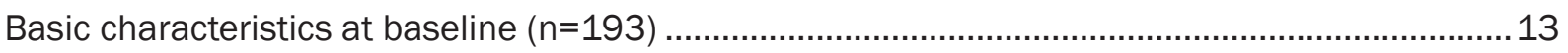

Comparisons of those retained and those lost to follow-up........................................................ 14

Comparison of population by modality at HIV care and treatment registration ..............................15

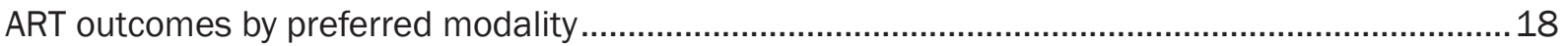

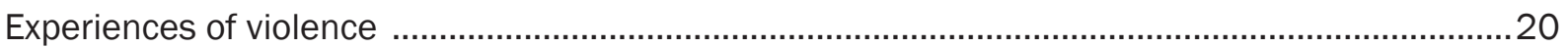

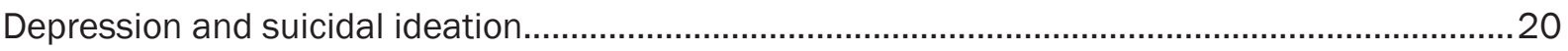

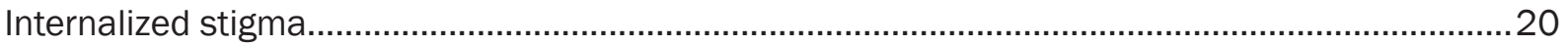

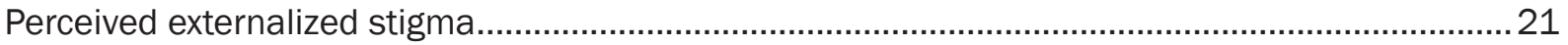

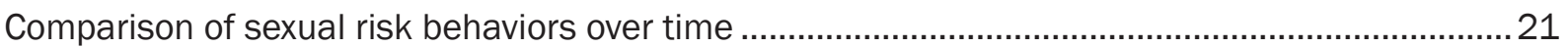

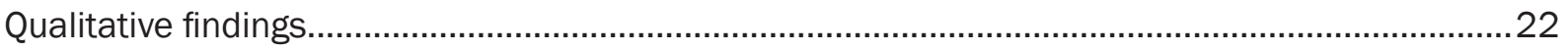

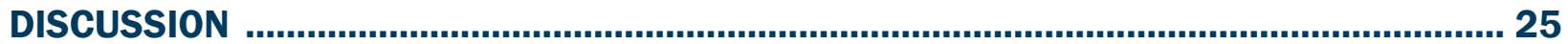

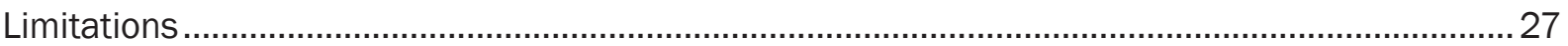

CONCLUSION AND RECOMMENDATIONS..................................................................... 28

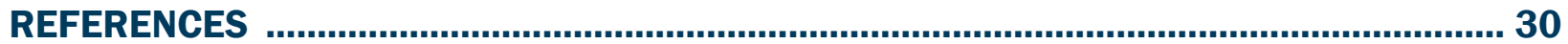




\section{ACRONYMS}

$\begin{array}{ll}\text { AIDS } & \text { Acquired immune deficiency syndrome } \\ \text { ART } & \text { Antiretroviral therapy } \\ \text { DIC } & \text { Drop-in center } \\ \text { FSW } & \text { Female sex worker } \\ \text { GBV } & \text { Gender-based violence } \\ \text { HIV } & \text { Human immunodeficiency virus } \\ \text { LINKAGES } & \text { Linkages across the Continuum of HIV Services for Key Populations Affected by HIV } \\ \text { MOH } & \text { Ministry of Health } \\ \text { MOHSW } & \text { Ministry of Health and Social Welfare } \\ \text { MSM } & \text { Men who have sex with men } \\ \text { NACP } & \text { National AIDS Control Programme } \\ \text { PLHIV } & \text { People living with HIV } \\ \text { PEPFAR } & \text { President's Emergency Plan for AIDS Relief } \\ \text { STI } & \text { Sexually transmitted infection } \\ \text { TB } & \text { Tuberculosis } \\ \text { USAID } & \text { United States Agency for International Development } \\ \text { WHO } & \text { World Health Organization } \\ \text { VL } & \text { Viral load }\end{array}$




\section{EXECUTIVE SUMMARY}

\section{INTRODUCTION}

In the 2016 Consolidated Guidelines for Managing Antiretroviral Therapy (ART), the World Health Organization (WHO) recommends a differentiated approach for designing ART services to reflect the specific preferences and needs of various risk groups of people living with HIV (PLHIV). In response, the Population Council and partners (through Project SOAR) assessed preference and early effectiveness of a community-based ART program for HIV-positive female sex workers (FSWs) in Malawi. In this model, ART services were provided through drop-in centers (DICs) that provided FSW-friendly services.

\section{METHODS}

From June to August 2018, we recruited a cohort of FSWs via community testing events, peer outreach, and referrals from HIV testing services in Malawi's Blantyre and Mangochi districts. Blantyre and Mangochi are part of the Southern region, which has the highest burden of HIV in the country. At recruitment, participants were either ART-naïve or had previously defaulted from ART treatment for at least 90 days. FSW participants were given the option to initiate treatment through either health facilities or DICs, and could choose to change modalities during the followup period. Participants were interviewed again after 12 months, and their routine health records were collected to assess viral suppression.

\section{RESULTS}

\section{Recruitment}

We recruited 194 participants at baseline; 59 percent lived in Blantyre. Follow-up interviews were completed with 87 percent of the sample $(n=167)$. The median age was 25 years old.

\section{Baseline characteristics}

Nearly one in five participants (18\%) had previously initiated and defaulted in care. One in four had known their HIV status for over three months but were not currently on treatment. Another 25 percent had known their status for at least a week, but less than three months.

While over 80 percent of FSWs reported using condoms at last sex with a paying client, of the 125 participants (65\%) who reported having one or more non-paying partners in the past three months, nearly two-thirds said that they had not used a condom at last sex with a non-paying partner. Few had discussed HIV status with their non-paying partner; only 18 percent knew their partner's HIV status. One-third of participants said that they had traveled to one or more other communities in order to sell sex. 


\section{DIC model shows better ART initiation}

All clients initially registered in HIV care and support services: 69 percent at a DIC and 31 percent at health facilities. Those who registered at a DIC were more likely to have actually initiated ART compared to those who initiated at health facilities (100\% vs. $92 \% ; p=0.002)$.

\section{Three ART service utilization patterns were identified}

Some study participants did not exclusively use one service delivery model. Of those who initiated care, three-quarters used either health facilities (38\%) or DICs (37\%) exclusively. However, the remaining 25 percent collected their ART medication through a combination of health facilities and DICs. Clients who registered for care and treatment services at Ministry of Health (MOH) sites were more likely than those who registered at a DIC to collect their ART medication exclusively through health facilities (68\% vs. $27 \%$ ), while those who registered at a DIC were more likely than those who registered at a health facility to collect medication either only through DICs (46\% vs. $28 \%$ ) or through a combination of DICs and health facilities (28\% vs. $4 \%$ ).

\section{Moderate to high levels of ART retention in all utilization models}

Among those who initiated ART, self-reported retention at one year was similar in both groups (90\% at DIC and $88 \%$ at facilities; $p=0.446$ ). At endline, 79 percent of participants reported that they had completed at least one drug pickup in the past six months. However, stratifying by service utilization pattern, 12-month retention was highest among exclusive DIC clients compared to facility-based or mixed-site clients ( $100 \%$ vs. $87 \%$ vs. $87 \%$; $p=0.026)$.

\section{Viral load (VL) tests were not frequently documented}

Among the 133 clients who had completed a drug pickup visit within the six months preceding our endline survey, only 23 percent of participants $(n=30)$ had a VL test result documented in their health records. When asked, 40 percent of participants reported that they had received a VL test. Clients who had ever collected ART medication through a DIC were nearly twice as likely to have documented VL results compared to those who exclusively collected their ART medication from health facilities ( $27 \%$ vs. $14 \%$; $p=0.08$ ).

\section{Viral suppression was high}

Although only 30 participants had test results recorded in their health records, of these, 90 percent were virally suppressed. However, this should be interpreted with caution because of a small sample size.

\section{Condom use was high among paying partners but low among steady partners}

However, approximately two-thirds of participants reported having a non-paying partner. Among these, over two-thirds considered their partner to be "steady," while the remainder described their partner as "casual." Half of participants with casual partners reported using condoms at last sex, whereas only 30 percent of those with steady partners reported using condoms at last sex with this partner. 


\section{Many reported experiencing external stigma}

Over half (54\%) of endline participants felt that other people held at least one of the seven common stigmatizing attitudes toward PLHIV. The most frequent responses were that most people were uncomfortable around someone living with HIV (43\%) or treat PLHIV differently than non-PLHIV (43\%).

\section{High levels of perceived internalized HIV-related stigma}

FSWs in both arms reported fairly high levels of internalized stigma at all time points. The most frequent responses were that participants hid their HIV status from others (40\%) or felt that it was difficult to tell others about their HIV infection (42\%).

\section{Experiences of physical and sexual violence were frequent but decreased over time}

Many participants reported experiencing physical (33\%) or sexual violence (19\%). However, reports of both types of violence dropped between baseline and endline (at endline, physical: $20 \% ; p<0.001$, sexual $7 \% ; p=0.021$ ).

\section{Participants had high levels of depression}

Nearly a quarter of participants reported symptoms of moderate to severe depression at baseline (23\%). Prevalence of depression also declined between baseline (23\%) and endline (13\%; $\mathrm{p}=0.017$ ). This contrasts with a recent study (Udedi 2018) of newly-diagnosed PLHIV in the general population in Malawi, where only 6 percent were classified as having moderate-to-severe depression.

\section{The DIC model is appealing to FSWs}

The quantitative and qualitative data indicate FSW's preference for the DIC model compared to health facility. Over two-thirds of study participants chose to register for HIV care and treatment services at a DIC, while the remaining registered at health facilities. After one year, over half completed their last drug refill visit at a DIC, and nearly two-thirds had accessed both facility- and DIC-based ART services since registering in care. Qualitative interviews with DIC clients indicated that they also found the DICs, which are located near large FSW hotspots, easier to access, and the providers were caring and understanding. FSWs also preferred the privacy that the DICs offered over health facilities, because DICs are often not crowded.

\section{CONCLUSIONS}

The findings indicate a considerable gap in linkage to, and retention in, ART services among FSWs, and differentiated models of HIV care may help fill this gap. Our pilot suggests DICs are an acceptable alternative to facility-based ART services for FSWs, particularly when they are convenient to the client's homes or places of business. DICs and their associated outreach services appear to facilitate ART initiation for FSWs and may effectively support achieving 
treatment retention and viral suppression. Findings suggest DICs may play a useful role in differentiated care models for FSWs. Greater emphasis is needed on understanding the gap in VL testing and documentation of VL testing results. 


\section{INTRODUCTION}

Malawi has a generalized HIV epidemic with a prevalence between 9 percent and 11 percent among people aged 15 to 49 years (Konate et al. 2011; World Health Organization [WHO] 2014). UNAIDS estimates that there are 1.1 million people living with HIV (PLHIV) in Malawi, and 34,000 new HIV infections occurred in 2014 (Konate et al. 2011). HIV prevalence is much higher among key populations: 63 percent among female sex workers (FSWs) (Ministry of Health and Social Welfare [MOHSW] and National AIDS Control Programme [NACP; Tanzania] 2014), and 21 percent in men who have sex with men (MSM) (MOHSW and NACP 2014). In 2015, the government of Malawi passed its National HIV Prevention Strategy (2015-2020), aiming to reduce HIV infections to reach the UNAIDS 90-90-90 targets (Rosen and Fox 2011). This strategy recognizes the need to develop HIV prevention and treatment programs specifically for key populations, including FSWs and MSM (Konate et al. 2011). Malawi was one of the first countries to adopt recommendations from the 2014 and 2015 Treatment Guidelines of the WHO to treat PLHIV as early as possible. To improve early detection of treatment failure, Malawi has adopted viral load (VL) monitoring of patients on ART at six months after initiating ART and at 24-month intervals thereafter.

Despite the progress and efforts to improve linkages to, and retention in, treatment, and to reduce HIV transmission, it is estimated that in 2015 only 67 percent of those in need of ART in Malawi were on ART. Among the approximately 750,000 patients who had ever initiated ART, only 69 percent were retained at the end of 2014; 21 percent had been lost to follow-up, and 9 percent were known to have died (Konate et al. 2011). FSWs face even greater challenges than the general population in accessing HIV care and treatment services, and therefore their treatment outcome may be worse compared to the general population. In the larger context of sub-Saharan Africa, several systematic reviews have consistently shown major attrition along each step of the HIV cascade. In particular, less than half of individuals not yet eligible for ART were retained in pre-ART care, and only two-thirds of ART-eligible individuals initiated ART (Lancaster et al. 2016; Scorgie et al. 2013; Research to Prevention [R2P] 2013; MOHSW and NACP 2015). Commonly cited barriers included stigma, long distance to clinics, inability to afford transport costs, long waiting times, and crowded health facilities due to shortage of health care workers. Key populations, including FSWs, face even greater challenges than the general population in accessing HIV care and treatment services, mainly due providers' lack of knowledge of and sensitivity to key populations' specific needs, and additional layers of stigma and discrimination related to their profession, behaviors, and/or sexual identity (National Statistical Office and ICF Macro 2011).

There is growing evidence that community-based services are critical components of HIV programming for key populations (Konate et al. 2011; Lancaster et al. 2016; Mountain et al. 2014; Bemelmans et al. 2014; Dave et al. 2019; Govindasamy et al. 2014; Havlir et al. 2019; Kerrigan et al. 2017; Koenig et al. 2017). Community models may include the use of outreach, mobile services, DICs, peer educators/navigators, community support groups, and community health workers. Some studies have shown that peer outreach models can increase HIV 
knowledge, condom use, and HIV testing among sex workers in sub-Saharan Africa (National Statistical Office and ICF Macro 2011; UNAIDS 2015; National Statistical Office 2014). Other studies have shown improved HIV treatment outcomes with the use of community health workers, including uptake of HIV services, retention in care, and increased dignity and quality of life of PLHIV (Govindasamy et al. 2014; Havlir et al. 2019; Pearson et al. 2011; Mwai et al. 2013). Additionally, the WHO Consolidated Guidelines for Key Populations recommends service integration (for clients to receive the services they need in one place), decentralization (to offer services closer to where the target populations are), and task shifting approaches based on initial successes observed in other countries, including Kenya, Ghana, Nigeria, and Uganda (Tun et al. 2019). In particular, the WHO recommends several solutions to make access to ART easier, more acceptable, and more effective for FSWs. These include: clinical services at sites located near places of sex work; flexible clinic hours (weekends, evenings); emergency drug pick-ups; patientheld records for sex workers who may seek ART at different sites; and non-judgmental staff attitudes (Lancaster et al. 2016; Mwai et al. 2013).

FHI 360 is leading the LINKAGES project, which aims to reach key populations, provide HIV prevention and testing services, link HIV-positive key population members to care and treatment services, and improve their retention in HIV care. The LINKAGES project supports key populationfocused HIV care and treatment organizations through technical assistance, training of providers in quality services, monitoring and evaluation, stigma reduction, community outreach and active referrals to services, enhanced follow-up for ART clients, integrated services, and establishment of DICs.

Malawi has been a leader in developing innovative approaches to optimizing HIV service delivery, including community-based ART through PLHIV groups, fast-track refills, and use of key population-friendly platforms such as DICs. One example is the model implemented by Pakachere Institute of Health and Development Communication (Pakachere), a local health-focused NGO. Pakachere uses their DICs to provide ART services to key populations in Malawi's Blantyre and Mangochi districts. A key feature of this pilot was that the ART services were provided by clinicians and nurses from government-run health facilities who would deliver medication to ART clients at the DICs on specific days of the week. These health care professionals also attended community outreach events led by the DICs to provide same-day initiation services to FSWs who had been identified as HIV-positive. At the time this study was developed, this DIC model had only been recently introduced in Malawi, and thus had not yet been systematically evaluated. Therefore, the Population Council and partners (through Project SOAR) conducted this study to assess whether acquiring ART medication through community-based DICs would appeal to FSWs in this context, to describe any observed effects on treatment outcomes, and to identify opportunities for improvement should this model be selected for future scale-up. 


\section{METHODOLOGY}

\section{OBJECTIVES}

This evaluation assessed the feasibility, acceptability, and preliminary effects of the communitybased ART service delivery model for FSWs supported by the LINKAGES project in Malawi, compared to centralized/government-managed ART services in health facilities.

\section{Specific objectives}

1. Assess FSW preference and acceptance of ART service modalities between: (a) LINKAGESsupported DIC clinics, and (b) government or other area health services/facilities that are not supported by LINKAGES.

2. Estimate performance of ART services provided through LINKAGES-supported DICs on the basis of four key indicators:

a. Enrollment in care: Proportion of HIV-seropositive FSWs recruited into the study registered for HIV care and treatment services within 30 days of testing HIV-positive and recruited into the study

b. Treatment initiation: Proportion of individuals initiating ART treatment within 60 days of enrollment in HIV care

c. Retention in treatment: Proportion of individuals retained in treatment at 12 months after ART enrollment

d. Treatment adherence: Proportion of individuals adhering to ART treatment measured by: (1) self-report and (2) viral suppression at 12 months (from clinic records)

3. Gather feedback from ART clients about the community ART service delivered through DICs.

4. Describe sexual risk behaviors, self-stigmatizing beliefs and perceptions, and experiences with physical and sexual violence.

\section{STUDY DESIGN}

This was a mixed-method implementation science study using a prospective cohort design, in which baseline data were collected from participants after they had tested HIV-positive but before ART enrollment, and follow-up interviews were completed 12 months later. We then invited a subsample of cohort participants to participate in in-depth interviews so we could better understand their service preferences and experiences with the ART services they received. Finally, we conducted qualitative interviews with health care providers to understand the operational aspects of providing HIV care to PLHIV within these modalities and provide additional context and recommendations on how to scale up community-based ART delivery. 
To estimate the sample size for this study, we first obtained retrospective service volume data from Pakachere's monitoring and evaluation system for the three DICs in Blantyre and two in Mangochi. From these data, we found that 324 HIV-positive FSWs were identified at the five targeted locations between March and September 2018. Due to time and financial considerations, study recruitment was planned to take place over a three-month period. We therefore determined that it would first be necessary to recruit all FSWs who were identified as HIV-positive through Pakachere's outreach testing activities. From these data we then estimated that the maximum number of participants that could be feasibly recruited was 200 , which, assuming 30 percent attrition, would allow us to detect differences of at least 13 percent between baseline and endline. To further ensure we were able to reach our targeted sample size, we coordinated with Pakachere to conduct additional outreach testing events during the cohort recruitment period to increase testing volume.

\section{DESCRIPTION OF INTERVENTION}

In Malawi, the LINKAGES Project provided HIV counseling and testing services to FSWs through community-based mobile outreach services and through walk-in testing at affiliated DICs. LINKAGES outreach workers and peer educators counseled women who tested positive about their care and treatment options. The outreach workers then offered referrals and escort services to a choice of two ART service models: (a) LINKAGES-supported DICs, and (b) health facilities.

\section{Key population focused DICs}

Pakachere is a local non-governmental organization (NGO) specializing in health communication, especially sexual and reproductive health and HIV, and was an implementing partner on the USAID-funded LINKAGES program. At the time of this study, Pakachere managed the DICs in Blantyre and Mangochi that were selected for inclusion in this study, and received ongoing technical assistance from LINKAGES. Results from this study may inform the use and/or expansion of the DIC model for key populations under future projects.

DICs are satellite clinics, attached to larger health facilities, and often have fewer high-level clinical staff. At their inception, DICs were designed to be accessible, community-based locations that were considered a safe space for key populations, and delivered HIV prevention services; HIV counseling and testing; screening for sexually transmitted infections (STIS), cervical cancer, and tuberculosis (TB); family planning (FP) services; referral services for gender-based violence (GBV); and referrals to ART services for HIV-positive clients. Pakachere also provides escort, initiation support, and community-based follow-up services to HIV-positive clients.

A DIC (or "safe space") is a facility rented by the program for community members to:

1. Relax in a safe environment, e.g., for sex workers who wish to shower, rest, or make themselves up before or after work.

2. Meet one another and hold social activities and informal discussions, which are important components of building community cohesiveness.

3. Take part in structured activities and training for community empowerment and mobilization. 
4. Meet the program staff and receive program services such as HIV education, HIV counseling and testing, and other HIV and reproductive health services.

The DIC is often managed by the key population community to ensure it is key population-friendly. In March 2017, DICs in Blantyre and Mangochi started offering ART services to FSW.

\section{LINKAGES peer educators}

Under LINKAGES Malawi, peer educators are a cadre of community health workers that comprise FSW who are trained to link other FSWs to program services, including services at DIC facilities. Each peer educator is assigned a number of FSWs in their community, with whom they typically meet on a monthly basis. The peer outreach worker provides basic health education, discusses factors that put FSWs at risk of HIV, and provides information and needed prevention commodities (condoms and lubricant). Peer educators who are HIV-positive further support and encourage HIV-positive FSWs to manage their health through HIV routine appointments, ART adherence, and behavior change. Peer educators do not usually work full-time, but they receive an agreed monthly stipend to compensate them for their time, skill, and expenses related to their work.

\section{Health facilities}

Health facilities typically provide ART services to the general population. These health facilities often have a large client base, ranging from a few thousand to more than 20,000 clients (cumulative number) in large urban cities such as Blantyre. Compared to DICs, health facilities are often more crowded due to high client volume, and clients often have to wait longer for their services. Key populations attend ART services at these facilities, but are not always prioritized by staff and treated sensitively. LINKAGES partners do refer clients to government-run facilities. LINKAGES has provided respectful care training to the facility-based health care providers who deliver ART services to FSWs through the DICs. Otherwise, these public health facilities are not typically supported by LINKAGES activities.

\section{Key similarities between the two service modalities}

Study participants in both modalities received ART services according to national treatment guidelines, including pre-ART and adherence counseling, standard clinical and behavioral assessment and referrals, and required disclosure of HIV status to at least one person. VL testing for clients of both modalities also follows national treatment guidelines: the first VL test is performed at 6 months after ART initiation; the second 12 months after the first test, and then every 24 months thereafter.

\section{Distribution of ARV drugs through DIC}

Clinicians scheduled regular visits to DIC to initiate new patients on ART as well as conduct HIV routine exams, refill prescriptions and refer clients for further laboratory testing. 
Table 1 Comparison of ART service modalities during the study follow-up period

\begin{tabular}{|c|c|c|}
\hline & DIC & Government \\
\hline $\begin{array}{l}\text { Populations targeted or } \\
\text { prioritized for services }\end{array}$ & Key populations & $\begin{array}{l}\text { General population (key populations } \\
\text { attend, although often stigmatized and } \\
\text { discriminated) }\end{array}$ \\
\hline FSW-friendly providers & Yes & Some \\
\hline Client flow & Low client volume & Medium to high client volume \\
\hline $\begin{array}{l}\text { Peer/community } \\
\text { involvement in } \\
\text { supporting services }\end{array}$ & $\begin{array}{l}\text { Peer educator and outreach workers } \\
\text { are available onsite: one peer } \\
\text { educator/40 FSWs }\end{array}$ & $\begin{array}{l}\text { Peer educator and outreach workers are } \\
\text { not available onsite but can escort FSW to } \\
\text { health facilities }\end{array}$ \\
\hline Staffing & $\begin{array}{l}\text { Clinical staff include nurses; doctors } \\
\text { may be available }\end{array}$ & Clinical staff includes doctors and nurses \\
\hline ART initiation & Test and start available & Test and start available \\
\hline ART prescription & Doctor and nurses & Doctor and nurses \\
\hline ART drug pick-ups ${ }^{a}$ & $\begin{array}{l}1 \text { month for new patient } \\
3 \text { months for stable patient }\end{array}$ & $\begin{array}{l}1 \text { month for new patient } \\
3 \text { months for stable patient }\end{array}$ \\
\hline Record keeping & $\begin{array}{l}\text { Electronic medical record system is } \\
\text { not available }{ }^{b}\end{array}$ & $\begin{array}{l}\text { Electronic medical record system is available } \\
\text { among sites that have } 5,000+\text { clients }\end{array}$ \\
\hline
\end{tabular}

${ }^{a}$ Three-month ART prescriptions were available to stable clients throughout the study period. Although six-month prescriptions were rolled out nationally during this study, such long-duration prescriptions were not available through the DICs until Q4 2019.

${ }^{\mathrm{b}}$ Access to electronic medical records (EMR) have not been available through the DICs and data were not reliably being entered into the EMR system at the start of the study. By the end of the study, Pakachere had instituted practices to ensure and confirm that EMR data was being entered into the system.

\section{DATA COLLECTION METHODS}

The quantitative data collected comprise baseline and endline surveys conducted among a cohort of HIV-positive FSWs that were recruited from a census of all HIV-positive FSWs identified through the Pakachere DIC outreach activities. The surveys were supplemented with reviews of client health records contained at the DICs and associated health facilities to verify key treatment outcomes. These data were used to answer study objectives one (assess FSW preferences and acceptance of ART service modalities) and two (assess and compare how ART service modalities affect treatment linkage, enrollment, retention, and adherence). Qualitative in-depth interviews were used to gather clients' feedback about ART service at DICs.

\section{Data collection approaches}

The baseline cohort survey and record reviews were conducted between June and August 2018; endline data collection was conducted approximately 12 months later. Using LINKAGES routine monitoring and evaluation data, we estimated that we would be able to recruit about 200 eligible FSWs in both cities within the planned three-month period. 


\section{Baseline recruitment and baseline data collection}

At baseline, the LINKAGES team (peer recruiters and clinical staff) actively identified and referred eligible FSWs who met study eligibility criteria for recruitment. FSWs were reached through the following routine LINKAGES services:

1. FSWs tested at targeted community outreach by peer educators (via mobile moonlight and daylight testing).

2. Walk-in clients who tested positive at the DICs.

3. FSWs who had tested positive at other health facilities and were referred to the DICs.

4. Defaulter tracing activities led by peer educators at each DIC.

When an HIV-positive FSW was referred to the research assistant (after post-test counseling), the research assistant screened for the following eligibility criteria: a) over 18 years of age; $b$ ) had sold sex during the previous 6 months; c) was HIV seropositive and either ART naïve or had previously initiated ART but had stopped taking medication for at least 3 months; and d) intended to reside in the catchment area for the next 12 months. If the woman met these eligibility criteria and was interested in participating in the study, the research assistant obtained informed consent and enrolled the participant.

Information collected during the baseline interview included key sociodemographic characteristics, history of HIV testing and counseling, recent sexual activities, places FSWs often sell sex, perceived HIV risk, experience of violence, STI screening and testing, contraceptive use, and HIV service utilization (for those who have been previously diagnosed but were not yet on ART treatment).

\section{Endline data collection}

Endline interviews were conducted by trained research assistants at a DIC or other private location convenient to participants. Information collected in the follow-up interview was fairly similar to the baseline interview, except with some additional questions aiming to measure key treatment outcomes, intervention exposure, switch in service modality (self-reporting and verification from health passport), and experience with the services that clients receive.

Qualitative participants were selected based on age, education, which service modalities they chose at endline, and ART status (currently on ART vs. not on ART). We selected a total of 20 participants. They were interviewed to understand their experiences with the services they received (either DIC or health facilities).

\section{Routine health record review (endline)}

At 12 months, we extracted data regarding the timing of recent facility visits and results of their last VL test from their routine service records. 


\section{ETHICAL REVIEW}

All data collectors were trained so that they understood data collection procedures and research ethics. Data collectors were subjected to an evaluation and only those who rated highly were recruited to be part of the research team. Data collectors used tablet computers to complete survey interviews. Data collected was stored on tablet computers and backed up in real time on a data cloud host at the University of Malawi. Additional monitoring during data collection was provided by local PI and investigator as well as the study coordinator.

This study was reviewed and approved by both the Population Council IRB and the University of Malawi College of Medicine Research Ethics Committee (COMREC).

\section{DATA ANALYSIS}

\section{Quantitative data}

We used descriptive analysis to provide an overview of the study sample and characteristics of patients receiving care at DIC vs. health facilities. Bivariate comparisons of proportions were conducted using Pearson's chi-squared test; we used McNemar's test for paired observations (i.e., for variables measured at both baseline and endline). All analyses were conducted using Stata version 15.

\section{Qualitative data}

Study investigators read translated in-depth interview and focus group discussion transcripts to identify key themes related to positive and negative experiences with providing and receiving services, perceived changes after the introduction of ART, and barriers to care. Themes were coded and analyzed using Atlas.ti software. 


\section{KEY FINDINGS}

\section{RECRUITMENT}

At baseline, we recruited 193 eligible FSWs: 59 percent were from Blantyre district and 41 percent were from Mangochi district. At endline, 87 percent of the cohort were reinterviewed.

\section{BASIC CHARACTERISTICS AT BASELINE ( $\mathbf{N = 1 9 3 )}$}

Cohort participants ranged in age from 18-48 years, with a median age of 25 years (Table 2). Approximately two-thirds of participants reported completing some primary education; 25 percent had completed any secondary education, while 12 percent said they had never attended school. Two-thirds of participants $(66 \%)$ reported having two or more living children; 21 percent had one child, while 12 percent had no children. The median self-reported total monthly income was 60,000 Malawian Kwacha (US\$82), and 81 percent reported earning at least 75 percent of their income through sex work.

Nearly one in five participants (18\%) had previously initiated and defaulted in care. One in four had known their HIV status for over three months, but were not currently on treatment. Another 25 percent had known their status for at least a week, but less than three months. These findings suggest a considerable gap in linkage to, and retention in, ART services.

While over 80 percent of FSWs reported using condoms at last sex with a paying client, of the 125 participants (65\%) who reported having one or more non-paying partners in the past

Table 2 Basic demographics

\begin{tabular}{|c|c|}
\hline Variable & n (\%) \\
\hline \multicolumn{2}{|l|}{ Region } \\
\hline Blantyre & $114(59)$ \\
\hline Mangochi & $79(41)$ \\
\hline \multicolumn{2}{|l|}{ Age } \\
\hline Median (IQR) & $25(22-29)$ \\
\hline \multicolumn{2}{|l|}{ Monthly income } \\
\hline Median (IQR) & $\begin{array}{c}60,000 \\
(40,000-100,000)\end{array}$ \\
\hline \multicolumn{2}{|l|}{ Education } \\
\hline None/never attended school & $12(6)$ \\
\hline Some primary & $133(69)$ \\
\hline Some secondary & $48(25)$ \\
\hline \multicolumn{2}{|l|}{ Number of living children } \\
\hline None & $24(12)$ \\
\hline One & $41(21)$ \\
\hline More than one & $128(66)$ \\
\hline \multicolumn{2}{|l|}{$\begin{array}{l}\text { ART status at time of } \\
\text { enrollment }\end{array}$} \\
\hline ART naive & $158(82)$ \\
\hline Defaulted on treatment & $35(18)$ \\
\hline \multicolumn{2}{|l|}{ HIV testing } \\
\hline Today & $102(53)$ \\
\hline$<3$ months & $42(25)$ \\
\hline$\geq 3$ months & $41(24)$ \\
\hline $\begin{array}{l}\text { Used condom at last sex with a } \\
\text { paying client }\end{array}$ & $158(82)$ \\
\hline Having a non-paying partner & $125(65)$ \\
\hline $\begin{array}{l}\text { Used condom at last sex with a } \\
\text { non-paying partner }(n=125)\end{array}$ & $46(37)$ \\
\hline $\begin{array}{l}\text { Knew partner's HIV status } \\
(n=125)\end{array}$ & $21(17)$ \\
\hline $\begin{array}{l}\text { Traveled outside of the region } \\
\text { to sell sex }\end{array}$ & $64(33)$ \\
\hline
\end{tabular}


three months (not shown), nearly two-thirds said that they had not used a condom at last sex with a non-paying partner. Few had discussed HIV status with their non-paying partner; only 17 percent knew their partner's HIV status. One-third of participants said that they had traveled to one or more other communities in order to sell sex.

\section{COMPARISONS OF THOSE RETAINED AND THOSE LOST TO FOLLOW-UP}

In terms of population demographics, the 25 participants who were lost to follow-up (LTFU) were not significantly different from those who were retained at endline. Comparing those retained versus LTFU, participants did not vary significantly in terms of age, (25 years vs. 23 years; $p=0.997$ ), or school attendance ( $5 \%$ vs. $12 \%$; $p=0.278$ ). Likewise, prior ART initiation and default was similar: 19 percent of retained participants had ever initiated ART, compared to 12 percent of those lost to follow-up ( $p=0.579$ ). Participants who received their HIV-positive diagnosis on the same day as their enrollment in the study comprised a greater proportion of those who were lost to follow-up (68\%) compared to the retained participants (51\%); however, despite the considerable apparent difference, it was non-significant $(p=0.277)$.

\begin{tabular}{|c|c|c|c|c|}
\hline Variable & $\begin{array}{c}\text { Retained } \\
(n=168) \\
n(\%)\end{array}$ & $\begin{array}{c}\text { LTFU }(n=25) \\
n(\%)\end{array}$ & p-value & $\begin{array}{c}\text { Total }(\mathrm{N}=193) \\
n(\%)\end{array}$ \\
\hline \multicolumn{5}{|l|}{ Region } \\
\hline Blantyre & $101(60)$ & $13(52)$ & 0.411 & $114(59)$ \\
\hline Mangochi & $67(40)$ & $12(48)$ & & $79(41)$ \\
\hline \multicolumn{5}{|l|}{ Age } \\
\hline Median (IQR) & $25(22-30)$ & $23(22-28)$ & $0.997 *$ & $25(22-30)$ \\
\hline \multicolumn{5}{|l|}{ Education } \\
\hline None/never attended school & $9(5)$ & $3(12)$ & $0.278^{\dagger}$ & $12(6)$ \\
\hline Some primary & $113(68)$ & $20(72)$ & & $133(69)$ \\
\hline Some secondary & $44(27)$ & $4(16)$ & & $48(25)$ \\
\hline \multicolumn{5}{|l|}{ Number of living children } \\
\hline None & $22(13)$ & $2(8)$ & $0.809 \dagger$ & $24(12)$ \\
\hline One & $35(21)$ & $6(24)$ & & $41(21)$ \\
\hline More than one & $111(66)$ & $17(61)$ & & $128(66)$ \\
\hline \multicolumn{5}{|l|}{ ART status at time of enrollment ${ }^{\dagger}$} \\
\hline ART naive & $136(81)$ & $22(88)$ & $0.579^{\dagger}$ & $158(82)$ \\
\hline Defaulted on treatment & $32(19)$ & $3(12)$ & & $35(18)$ \\
\hline \multicolumn{5}{|l|}{ Time since initial diagnosis $^{\dagger}$} \\
\hline Today & $85(51)$ & $17(68)$ & $0.277^{\dagger}$ & $102(53)$ \\
\hline $0-3$ months & $42(25)$ & $3(12)$ & & $45(23)$ \\
\hline$\geq 3$ months & $41(24)$ & $5(20)$ & & $21(24)$ \\
\hline
\end{tabular}

†Fisher's exact test *Non-parametric test of medians 


\section{COMPARISON OF POPULATION BY MODALITY AT HIV CARE AND TREATMENT REGISTRATION}

During endline interviews, we collected information from study participants on where they initially registered in HIV care and treatment services. Of the 168 participants who were interviewed at endline, 69 percent had opted to register for HIV care and treatment services at a DIC, while the remaining 31 percent went to a health facility to register. We compared baseline characteristics between these two groups of participants. Participants living in Blantyre were 3.7 times as likely to have registered in care at a DIC compared to those in Mangochi, however, this may have been due to early staffing challenges at the DICs in Mangochi. Those who registered at a health facility were marginally more likely to have previously defaulted on ART treatment (DIC: $16 \%, n=18$ vs. health facility: $27 \%, n=14 ; p=0.082)$. Otherwise, the participants were generally similar regardless of where they chose to register (Table 4).

They ranged in age from 18-48 years, and had a median age of 25 years. Approximately twothirds of participants in either group reported completing some primary education; 26 percent had completed any secondary education, while 5 percent said they had never attended school. Number of living children did not differ significantly either, with nearly two-thirds of participants (66\%) reporting that they had more than one. Rates of condom use at last sex with both clients (83\%) and non-paying partners (36\%) were also similar between the two groups, as was knowledge of a non-paying partner's HIV status (18\%). About one-third of both groups said they had traveled outside their home district to sell sex in the past six months. The proportion of clients who had received an initial HIV test prior to registering for HIV care and treatment services was comparable regardless of whether they registered at a DIC or a health facility. 
Table 4 Baseline characteristics by modality at HIV care and treatment registration

\begin{tabular}{|c|c|c|c|c|}
\hline Variable & $\begin{array}{l}\text { Registered at DIC } \\
(n=116) \\
n(\%)\end{array}$ & $\begin{array}{c}\text { Registered at health } \\
\text { facility }(n=52) \\
n(\%)\end{array}$ & p-value & $\begin{array}{l}\text { Total }(n=168) \\
n(\%)\end{array}$ \\
\hline \multicolumn{5}{|l|}{ Region } \\
\hline Blantyre & $81(70)$ & $20(39)$ & $<0.0001$ & $101(60)$ \\
\hline Mangochi & $35(30)$ & $32(62)$ & & $67(40)$ \\
\hline \multicolumn{5}{|l|}{ Age } \\
\hline Median (IQR) & $24(21-29)$ & $25(22-30)$ & $0.860 *$ & $25(22-29.5)$ \\
\hline \multicolumn{5}{|l|}{ Monthly income } \\
\hline Median (IQR) & $\begin{array}{c}60,000 \\
(40,000-100,000)\end{array}$ & $\begin{array}{c}79,000 \\
(40,000-150,000)\end{array}$ & $0.243 *$ & $\begin{array}{c}60,000 \\
(40,000-100,000)\end{array}$ \\
\hline \multicolumn{5}{|l|}{ Education } \\
\hline $\begin{array}{l}\text { None/never attended } \\
\text { school }\end{array}$ & $4(4)$ & $5(10)$ & 0.242 & $9(5)$ \\
\hline Some primary & $82(71)$ & $33(64)$ & & $115(69)$ \\
\hline Some secondary & $30(26)$ & $14(27)$ & & $44(26)$ \\
\hline \multicolumn{5}{|l|}{ Number of living children } \\
\hline None & $15(13)$ & $7(14)$ & 0.282 & $22(13)$ \\
\hline One & $28(24)$ & $7(14)$ & & $35(21)$ \\
\hline More than one & $73(63)$ & $38(73)$ & & $111(66)$ \\
\hline \multicolumn{5}{|l|}{$\begin{array}{l}\text { ART status at time of } \\
\text { enrollment }\end{array}$} \\
\hline ART naive & $98(85)$ & $38(73)$ & 0.082 & $136(81)$ \\
\hline Defaulted on treatment & $18(16)$ & $14(27)$ & & $32(19)$ \\
\hline \multicolumn{5}{|l|}{ Time since initial diagnosis } \\
\hline Today & $59(51)$ & $26(50)$ & 0.855 & $85(51)$ \\
\hline $0-3$ months & $30(26)$ & $12(23)$ & & $42(25)$ \\
\hline$\geq 3$ months & $27(23)$ & $14(27)$ & & $41(24)$ \\
\hline $\begin{array}{l}\text { Condom use at last sex with } \\
\text { a paying client }\end{array}$ & $93(80)$ & $46(89)$ & 0.189 & $139(83)$ \\
\hline $\begin{array}{l}\text { Condom use at last sex with } \\
\text { a non-paying client }\end{array}$ & $28(34)$ & $12(41)$ & 0.486 & $40(36)$ \\
\hline Knew partner's HIV status & $14(17)$ & $6(21)$ & 0.663 & $20(18)$ \\
\hline $\begin{array}{l}\text { Traveled outside of the } \\
\text { region to sell sex }\end{array}$ & $37(32)$ & $18(35)$ & 0.728 & $55(33)$ \\
\hline
\end{tabular}

*Non-parametric test of medians

\section{PREFERENCE OF SERVICE MODALITIES (AFTER ENROLLIMENT)}

After testing positive, 69 percent $(n=116)$ of study participants chose to register in HIV care and treatment services at a DIC, while the remaining 31 percent $(n=52)$ registered at health facilities 
(Tables $4 a$ and b). During endline surveys, we conducted oral histories with all participants to identify all sites where they had collected ART medication during the preceding 12 months. Through this process, we found that there were three basic usage patterns: nearly three-quarters of participants had visited either only DICs (35\%) or only health facilities (36\%). About one-quarter of participants (24\%) reported accessing ART services at both DICs and health facilities. Another eight participants had either never initiated ART $(2 \%, n=4)$ or had never completed any ART pickup visits $(2 \%, n=4)$.

Table 4a ART service choice

\begin{tabular}{|c|c|}
\hline Variable & n $(\%)$ \\
\hline \multicolumn{2}{|l|}{$\begin{array}{l}\text { Location of registration in care } \\
\text { and treatment services }\end{array}$} \\
\hline DIC & $116(69)$ \\
\hline Other health facility & $52(31)$ \\
\hline \multicolumn{2}{|l|}{$\begin{array}{l}\text { Accessed ART services in past } 12 \\
\text { months }\end{array}$} \\
\hline Health facility only & $61(36)$ \\
\hline DIC and health facility & $40(24)$ \\
\hline DIC only & $59(35)$ \\
\hline $\begin{array}{l}\text { Never initiated ART or did not } \\
\text { collect medication }\end{array}$ & $8(5)$ \\
\hline
\end{tabular}

Table 4b ART service choice by registration site type

\begin{tabular}{|c|c|c|c|}
\hline \multirow{2}{*}{$\begin{array}{l}\text { Registration } \\
\text { site }\end{array}$} & \multicolumn{3}{|c|}{ Service use in past 12 months } \\
\hline & $\begin{array}{c}\text { Health facility } \\
\text { only } \\
n(\%)\end{array}$ & $\begin{array}{c}\text { DIC and } \\
\text { health facility } \\
n(\%)\end{array}$ & $\begin{array}{c}\text { DIC only } \\
n(\%)\end{array}$ \\
\hline $\mathrm{MOH}$ sites & $31(68)$ & $2(4)$ & $13(28)$ \\
\hline DIC & 30 (26) & 32 (28) & $52(46)$ \\
\hline
\end{tabular}

Among those who started treatment at health facility, over two-thirds (68\%) continued to collect their medication only through health facilities, while 28 percent subsequently switched to collecting their medications through only DICs, and a small minority (4\%) collected medication from both health facilities and DICs. Amongh those who registered at a DIC, 46 percent continued to collect their medication from only DICs, while 26 percent switched to collecting their medication only through a health facility, and 28 percent collected medication from both DIC and MOH sites. Thus, it appears that participants who initiated treatment at DICs were much more likely to use both modalities to collect medication than were participants who initiated treatment through a health facility.

This divergence in some clients' preferred ART service model may be driven in part by the migration patterns of FSWs. Figure 1 maps sites where clients were recruited (green) and where they reported having completed their most recent ART drug pickup visit (red) overlaid on a district-level map of Malawi. The size of each dot represents the total number of participants recruited or attending services at each site. The figure

Figure 1 Location of study participants at recruitment and last ART pickup visit

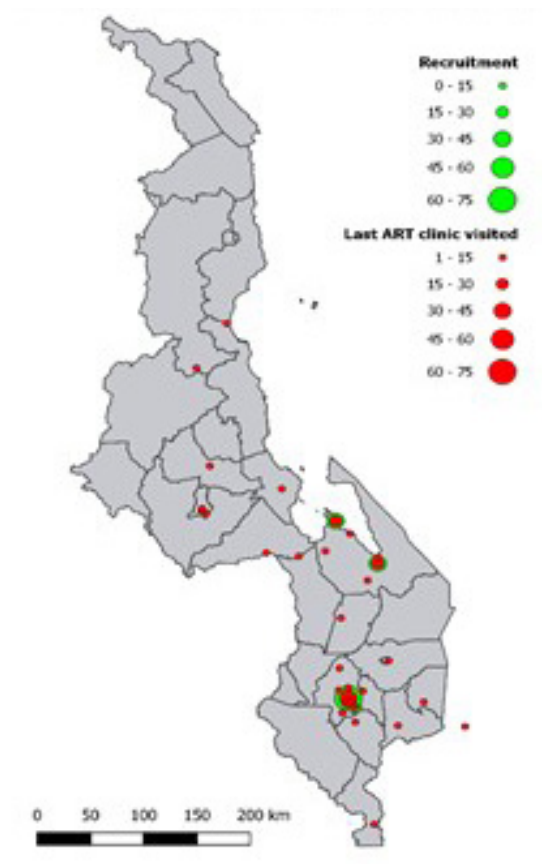


shows study participants traveled widely across the country. In some instances, participants traveled several hundred kilometers between their point of recruitment and their most recent facility visit. In fact, of the 159 participants who initiated care and subsequently picked up any medication, nearly one-quarter $(23 \%, n=37)$ had collected their medication while in a different district from where they had initially been recruited.

\section{ART OUTCOMES BY PREFERRED MODALITY}

\section{Linkage to treatment and same-day initiation (Table 5a)}

Of the 168 clients who completed baseline and endline interviews, all (100\%) registered for HIV care and treatment services at either a DIC or health facility. Of these, $163(98 \%)$ went on to initiate ART (Table 5a).

Treatment initiation was higher among those who registered in care at a DIC (100\%) compared to those who registered at a health facility $(92 \% ; p=0.002)$. Those who registered at a DIC were also more likely to receive same-day initiation (76\%) than those who registered at health facilities (55\%; $p=0.010)$.

Table 5a Comparison of ART outcomes by service modalities $(\mathrm{n}=168)$
\begin{tabular}{|lcccc|}
\hline Variable & $\begin{array}{c}\text { Registered at DIC } \\
(\mathrm{n}=116) \\
n(\%)\end{array}$ & $\begin{array}{c}\text { Registered at } \\
\text { health facility } \\
(n=52) \\
n(\%)\end{array}$ & $\begin{array}{c}\text { p-value } \\
\text { Initiated ART }\end{array}$ & $\begin{array}{c}\text { Total } \\
(\mathrm{n}=168) \\
n(\%)\end{array}$ \\
Received same-day initiation & $88(76)$ & $26(55)$ & 0.010 & $114(70)$ \\
Reported current ART use & $99(85)$ & $42(88)$ & 0.718 & $141(86)$ \\
\hline
\end{tabular}

†Fisher's exact test

\section{Retention and adherence (Table 5b)}

Table 5b shows treatment outcomes stratified by the three different participants' ART service access patterns: those who collected ART medication exclusively from a DIC $(n=65)$, those who collected ART medication exclusively from health facilities $(n=61)$, and mixed-model clientsthose who used a combination of both $(n=34)$. The eight clients who either never initiated care or reported never collecting ART medication were excluded.

Retention in treatment at one year: When stratifying by three service modalities, reporting of current usage was not statistically different (92\% DIC, $87 \%$ health facility, $82 \%$ mixed).

Adherence to treatment (Table $5 b$ ): In total, 41 percent of participants self-reported that they had missed any doses of their medication during the past 30 days. Among exclusive health facility users, 33 percent reported missing medication on one or more days, compared to 45 percent for mixed-model clients and 47 percent for those who only visited DICs; however, this was not 
a significant difference $(p=0.291)$. A considerable proportion of participants also reported that they had stopped taking their medication for longer than a month (17\%). Among exclusive users of health facilities and DICs, the proportion who stopped treatment for at least a month was 20 percent and 17\%, respectively. Among mixed-model clients, only 4 percent $(n=1)$ reported stopping treatment for a month or more $(p=0.136)$

\section{VL testing and viral suppression (Table 5b)}

To assess VL testing and suppression, we examined participant health passports during interviews and collected ART numbers and visit records from documentation stored at the DICs. We then visited the health facilities that serve the study participants to locate and extract data directly from the original ART client care cards. We were able to review 99 health passports. Of these, 19 had received a VL test and 11 had results recorded; 82 percent $(n=9)$ were virally suppressed. We also located ART records for 123 participants. Of these, 47 health records had evidence of a recent VL test, and 26 had results recorded for this test while 21 did not. Of the 21 without VL test results, 33 percent $(n=7)$ of tests had been conducted within 14 days of the interview, suggesting that the results may not yet have been released.

Of the 150 participants who had data from one or both sources, 30 (52 percent) had received a viral load test and had the results of that test documented in their records. All health facility clients were virally suppressed, compared to approximately 87 percent of DIC and mixed-model clients; however, this finding must be interpreted with caution due to the small sample size. These results are comparable to findings from survey data where 40 percent $(n=68)$ of participants recalled receiving a VL test, and 35 percent of those tested $(n=24)$ knew their most recent results. Of these, 88 percent $(n=21)$ said they were virally suppressed.

Table 5b ART adherence and viral suppression by DIC exposure among clients who completed $1+$ ART refill visits in past 6 months $(n=160)$

\begin{tabular}{|c|c|c|c|c|c|}
\hline & $\begin{array}{l}\text { Only collected ART } \\
\text { from health facility } \\
\qquad \begin{array}{c}(n=61) \\
n(\%)\end{array}\end{array}$ & $\begin{array}{l}\text { Collected ART from } \\
\text { DIC and health } \\
\text { facility }(n=34) \\
n(\%)\end{array}$ & $\begin{array}{l}\text { Only collected } \\
\text { ART from DIC } \\
\qquad(n=65) \\
n(\%)\end{array}$ & p-value & $\begin{array}{c}\text { Total } \\
(n=160) \\
n(\%)\end{array}$ \\
\hline $\begin{array}{l}\text { Missed any doses in } \\
\text { past } 30 \text { days }\end{array}$ & $16(33)$ & $13(45)$ & $26(47)$ & 0.291 & $55(41)$ \\
\hline $\begin{array}{l}\text { Stopped taking ART for } \\
30+\text { days during past } 6 \\
\text { months }\end{array}$ & $8(17)$ & $1(4)$ & $11(20)$ & 0.136 & $22(17)$ \\
\hline $\begin{array}{l}\text { Had VL results } \\
\text { documented in health } \\
\text { records (past } 6 \\
\text { months) } \\
\text { \$† }\end{array}$ & 7 (14) & $8(28)$ & $15(27)$ & 0.219 & $30(23)$ \\
\hline $\begin{array}{l}\text { Virally suppressed } \\
(<1,000 / \mathrm{ml})^{\S}\end{array}$ & $7(100)$ & $7(88)$ & $13(87)$ & $* * *$ & $27(90)$ \\
\hline Current ART use & $53(87)$ & $28(82)$ & $60(92)$ & 0.323 & $141(88)$ \\
\hline
\end{tabular}

\$Data extracted from health records; ${ }^{\dagger}$ denominator includes 10 participants for whom no health records were found $* * * p<0.001$ 
Figure 2 Experience of physical and sexual violence in past 12 months

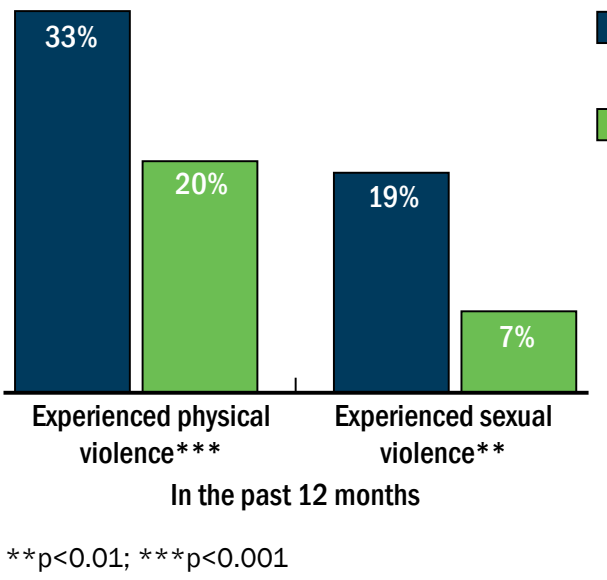

\section{EXPERIENCES OF VIOLENCE}

Baseline A high proportion of participants reported ( $n=193)$

having experienced physical or sexual violence at both baseline and endline; however, this did decrease significantly by endline (Figure 2). At baseline, one-third of participants (33\%) had been kicked, punched, or beaten within the last 12 months; 19 percent had been forced to have sex or engage in sexual acts against their will. By endline, reports of physical violence dropped to 20 percent $(p=0.0009)$, and sexual violence dropped to 7 percent $(p=0.001)$

\section{DEPRESSION AND SUICIDAL IDEATION}

Based on results of the PHQ-9 diagnostic instrument that was administered as part of the baseline and endline surveys, over one in five (23\%) FSWs reported symptoms consistent with moderate to severe depression during the previous week (Figure $3)$. Based on findings from a recent study (Udedi et al. 2018) of newly diagnosed PLHIV, the FSWs who participated in this study were nearly four times as likely to be depressed at baseline compared to other PLHIV. By
Figure 3 Prevalence of depression and recent suicidal ideation

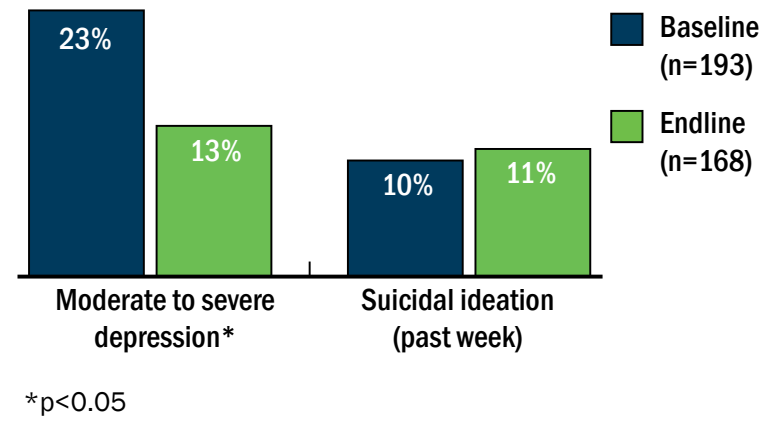

endline, prevalence of depression decreased by almost half (13\%). Approximately 10 percent of participants at baseline and endline said that they had thought they would be better off dead, or had thoughts about hurting themselves during the past week. In further bivariate analysis, moderate to severe depression was found to be associated with experiences of physical violence (OR 3.89; $p$ <.01) and sexual violence (OR: 3.15; $p=0.003$ ). Suicidal ideation or thoughts of selfharm was not associated with either of these types of experiences.

\section{INTERNALIZED STIGMA}

Internalized stigma was measured through a series of 10 agree/disagree questions measured at endline (Figure 4). The most frequent responses were that participants hid their status from others (40\%), or felt that it was difficult to tell others about their HIV infection (42\%). This corresponds closely to rates of non-disclosure of HIV status to non-paying partners (38\%). Other common responses were that being HIV-positive sometimes made participants feel worthless (30\%), and that people's attitudes toward PLHIV made them feel worse about themselves (32\%). 
Figure 4 Prevalence of internally stigmatizing attitudes (endline, $n=168$ )

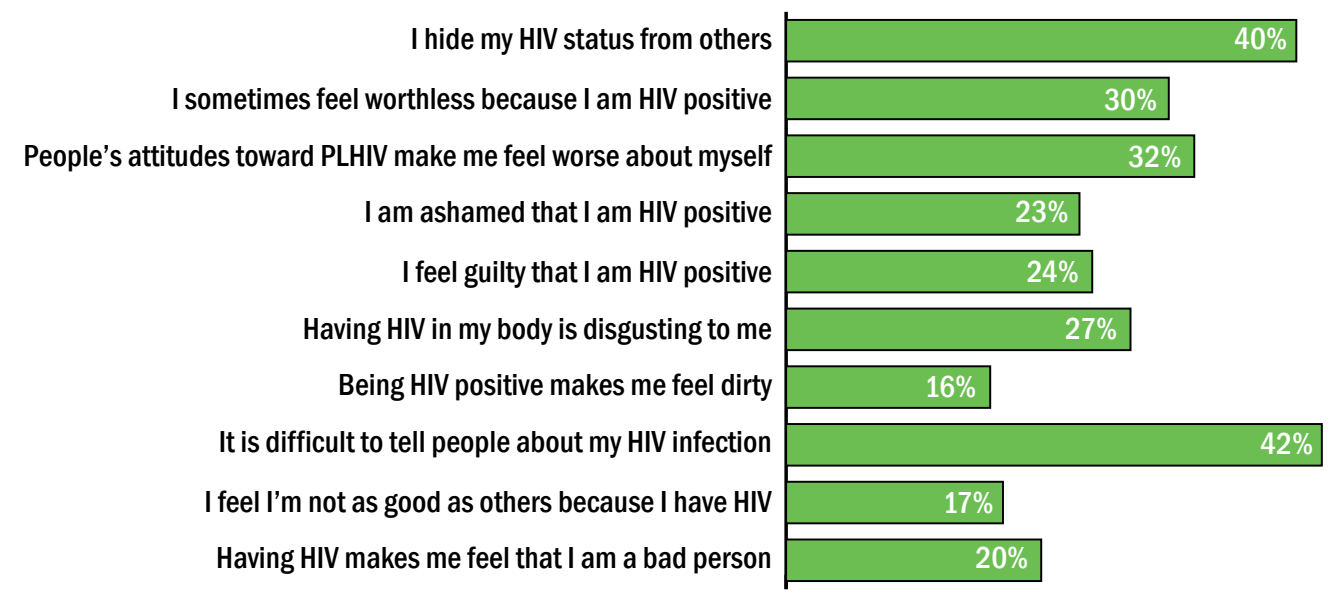

\section{PERCEIVED EXTERNALIZED STIGMA}

Perceptions of externalized stigma were measured through a series of seven agree/disagree questions (Figure 5). Over half (54\%) of endline participants agreed with at least one item in this scale, and 17 percent agreed with all seven statements, indicating high levels of external stigma. The most frequent responses were that most people were uncomfortable around someone living with HIV (44\%) or treat PLHIV differently than non-PLHIV (43\%). Other common responses were that most people reject PLHIV when others learn of their status (37\%), PLHIV often lose their jobs if their employers learn their HIV status (35\%), and most people think that someone living with HIV is disgusting (33\%).

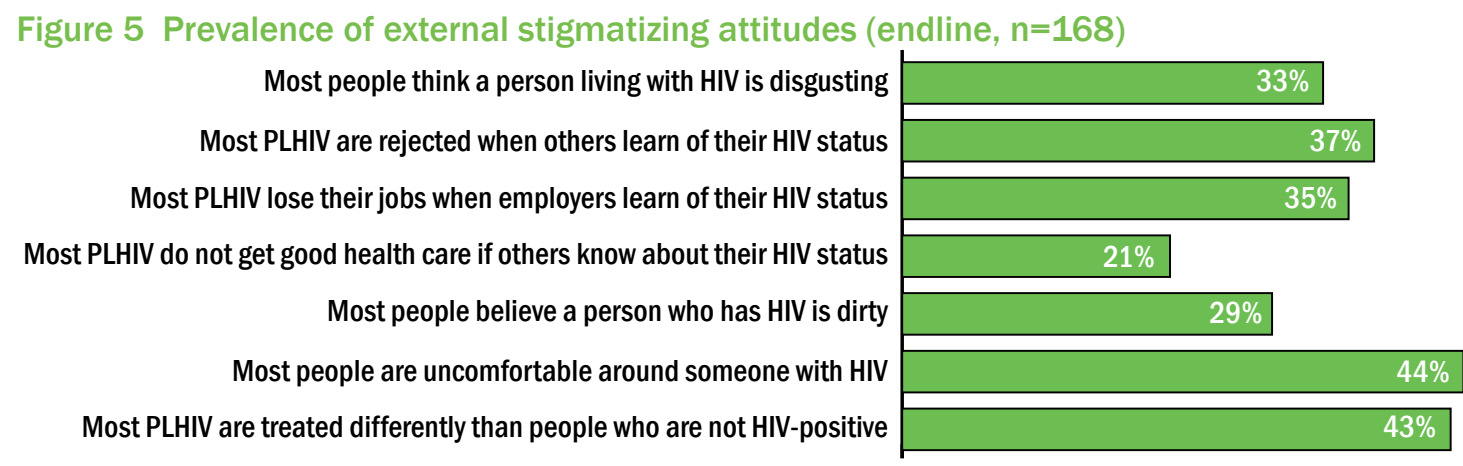

\section{COMPARISON OF SEXUAL RISK BEHAVIORS OVER TIME}

Table 7 examines changes in several key sexual risk behaviors over time. Condom use at last sex with a paying client are consistently high at both timepoints ( $82 \%$ vs. $83 \%$; $p=0.87$ ). Nearly twothirds did not use a condom the last time they had sex with a non-paying partner (63\% vs. $65 \%$; $p=0.73$ ). However, at endline considerably more knew their partner's HIV status ( $17 \%$ vs. $57 \%$, $\mathrm{p}<0.001)$; 44 percent knew their non-paying partner was HIV-positive, while 13 percent knew their partner was HIV-negative (Table 4). 
Table 7 Comparisons of sex work characteristics and sexual behavior between baseline and endline

\begin{tabular}{|lccc|}
\hline Variable & $\begin{array}{c}\text { Baseline } \\
(\mathrm{n}=193) \\
\mathrm{n}(\%)\end{array}$ & $\begin{array}{c}\text { Endline } \\
(\mathrm{n}=168) \\
\mathrm{n}(\%)\end{array}$ & p-value \\
$\begin{array}{l}\text { Used condom with last paying client } \\
\text { Yes }\end{array}$ & $158(82)$ & $109(83)$ & 0.870 \\
No & $35(18)$ & $23(17)$ & \\
Used condom at last sex with non-paying partner & & & \\
Yes & $46(37)$ & $42(35)$ & .733 \\
No & $79(63)$ & $79(65)$ & \\
Knew non-paying partner's HIV status & & & \\
Never discussed & $104(83)$ & $52(43)$ & $<0.001$ \\
HIV-negative & $10(8)$ & $16(13)$ & \\
HIV-positive & $11(9)$ & $53(44)$ & \\
\hline
\end{tabular}

\section{QUALITATIVE FINDINGS}

In-depth interviews with FSWs, peer-educators, and DIC staff yielded valuable perspectives on how FSWs access ART services and their experiences at both DICs and health facilities.

\section{Less stigmatization, less discrimination, and more convenience}

Many expressed concerns about lack of physical privacy at the central facilities, which combined with fears about unintentional disclosure while waiting for HIV care at central facilities. Many indicated that DIC are much more accepting of FSWs and that they would feel more open to discussing any health matter with providers at DICs. The flexible drug pickup feature was also appealing to FSWs.

I like the way the DIC conduct the clinic service here. I understand this is only for us sex workers and we feel comfortable with that, many people do not feel comfortable to be seen collecting ARVs.

When you go to a health facility, everyone knows that you have gone there for ART. At $D I C$, it is more private and people don't suspect that you are there to get ART.

Yes, I am really encouraged by seeing my friends and relatives enjoying stress free life, no worries and always happy. On top of that they are not even discriminated [against] because people have accepted them and they are respected. I can assure you that next week come what may, I will come for testing ready for the results comply with the advice to be given. 
They have been there for me, encouraging, advising as well as giving me hope in life.

As I said I used to be worried most of the times but through the help from the DIC staff I learnt that worries will affect my health living. To some extent I can say that I am as healthy as I am because of the help I have been getting from the DIC.

I find it very simple and easy to come for my refills because the DIC is very close to my home, I also do my business at night so am always free during the day time not only, that I plan and because this is always on plan I cannot manage to miss.

$-\mathrm{FSW}$

\section{DIC providers are committed to client confidentiality}

Privacy and confidentiality matter to HIV clients and sex workers, and there is a consensus from FSWs that DIC providers are committed to protecting their clients' occupation as sex workers and their HIV-positive status. Privacy concerns go hand in hand with concerns of being stigmatized or being unintentionally disclosed, and as a result FSWs feel that they can speak freely to their DIC providers. The providers themselves also stressed the importance of protecting the confidentiality of FSWs and PLHIV.

I miss going to Pakachere DIC simply because I do not have to meet people from the general public. I moved to Bvumbwe (government clinic) simply because of this pregnancy. I will go back to the DIC after I deliver.

The reason [I go here; DIC] is how friendly the people are. They treat people well and it makes me feel open to them which make me explain secret things to the doctor which I cannot disclose to anyone.

I came to the DIC and the nurse asked me the number of clients per day and I was able to share that. She also asked if I use protection every time I have sex and I was free to tell her everything.

When they come here, they are assured that whatever has been discussed here at the DIC does not go out. This is not always the case at $\mathrm{MOH}$ clinics. Apart from that, when we go to $\mathrm{MOH}$ facility, there is a section designed for ART....

-Provider

All the people who work with Pakachere signed an oath of confidentiality whereby they admit to seal the privacy of a sex worker they assist. This is because sex workers are very much interested in having their status protected and that is why this place is uniquely designed for sex workers. 


\section{Peer navigators provide a critical role in ART adherence support and retention.}

Lay health workers such as peer navigators play an important part of individuals' support networks and their responsiveness to patients' diverse medical and psychological needs influence patients' willingness to adhere to ART and remain in care.

I am very grateful to Pakachere for the best services they provide mainly for us

sex workers. It would be very hard for me personally to be going to the public

health facilities and be comfortable with the environment. I also thank them for the peer navigators who visit me to check with me how I am coping with ARVs.

The peer navigators visit me sometimes. They encourage me to come here for ART

and sometimes when my medication is about to run out they even come with me here [to DIC]. Some of them distribute condoms which is also helpful.

The peer navigators act more like a queen mother of our FSW clients and sometimes when FSWs go far away, they call peer navigators [to] collect medication for them.

-Provider

\section{Confidence and strong self-efficacy to commit to or maintain life-long ART were recurrent themes in the accounts of many FSWs.}

66

I accepted that this is going to be my life and if I want to live a healthy life I have to make sure I take medication everyday as such I make sure I shouldn't miss the day which I am supposed to come for ART.

To be honest, I cannot just stop taking the medications...like absolutely no it is impossible I can't.

I do manage [to pick up medications] because we have people who remind us about our [FSWs] dates to come here and collect our ARV pills. We have their numbers so when we are not sure as to when to see the nurse for ART service, we call them and they remind us. 


\section{DISCUSSION}

In August 2016, the government of Malawi officially adopted the WHO Test and Start policy of offering treatment to all individuals with HIV regardless of their health status. Additionally, Malawi has been a leader in developing innovative approaches to optimizing HIV service delivery, including providing community-based ART services through PLHIV groups, fast track refills, and use of key population-friendly platforms such as DICs. The DIC model was introduced shortly before the beginning of this study and had not been systematically evaluated to assess whether or how the model would appeal to targeted key populations. In response, we assessed preferences and preliminary effects of an ART service model for FSWs using DICs operated by Pakachere through support from the LINKAGES Program in Blantyre and Mangochi, Malawi. A key feature of this pilot is that the ART services were provided by clinicians and nurses who came from government-run facilities to deliver medication to patients at the DICs on specific days of the week. These health care professionals also attended outreach events led by the DICs to provide same-day ART initiation to FSWs identified as HIV-positive.

Baseline findings indicated a gap in HIV testing and treatment, as one-third of HIV-positive participants not on ART reported they had been positive for more than a month and a small proportion were on ART but recently dropped out. In addition, the risk of transmission from HIV-positive FSWs to their non-paying sex partners remain high because, although a majority of FSW reported having one or more non-paying partners, only one-third used condoms with these partners. Therefore, providing same-day ART initiation to all FSWs who test positive for HIV is critical. A community-based ART program such as the DIC model described in this study may serve as an important role in the strategy for closing the HIV care and treatment gap for FSWs. The one-year evaluation findings of this pilot demonstrate that ART provision through DICs can lead to higher ART initiation while maintaining high levels of ART retention and viral suppression, compared to ART services provided through government operated health facilities.

While nearly everyone in both models initiated ART, treatment initiation was significantly higher in the DIC model compared to the health facility model. Moreover, those who registered at a DIC were also more likely to receive same-day initiation (76\%) than those who registered at health facilities (55\%). This is likely due to the fact that DIC model makes treatment initiation logistically easier for patients, and there is strong peer support and early counseling from peer navigators. The difference in ART initiation between the two models also suggests that if the FSW has to go to another facility after testing positive (i.e., same-day ART initiation was not offered), we may miss the opportunity to place these individuals on treatment.

About half of survey participants reported receiving a VL test in the past six months, but fewer than one-quarter had a VL result documented in their health records. These data indicate that Malawi's national HIV program is not completing enough VL tests or properly documenting test results to accurately assess progress toward achieving 90 percent viral suppression among HIV-positive FSWs who are receiving treatment. The national guidelines require that ART clients receive their first VL test six months after ART initiation. But in reality, VL testing likely falls short 
of this target. Without a viral result, providers are not able to provide proper consultation to clients or manage their clients' ART effectiveness and adherence. A small-scale research study to understand more about the gap in VL testing results would be useful.

Our findings further suggest that accessing treatment through the DIC model may have minimal positive effect on either ART retention or adherence compared to health facilities. However, retention and viral suppression rates were fairly high in both study arms (nearly 90\%). The finding of a high viral suppression rate is similar to findings of two other SOAR studies in Namibia (Vu et al. 2019) and Tanzania (Tun et al. 2019), the PopART trial in Zambia and South Africa (Sabapathy 2017), and the most recent systematic review (Dave et al. 2019), and suggests that the effectiveness of care and treatment services is high regardless of which model was chosen.

FSWs in both groups reported fairly high levels of internalized stigma at all time points (approximately 20\% to 42\%, depending on scale items). The most frequent responses were that participants hid their status from others (40\%) or felt that it is difficult to tell others about their HIV infection (42\%). This corresponds closely to rates of non-disclosure of HIV status to nonpaying partners. Studies have shown that internalized stigma can manifest in a variety of ways, including low self-esteem, self-isolation, shame, withdrawal from seeking health services, and depression, which in turn can impact HIV treatment-seeking behaviors (Kalichman et al. 2009; Tomori et al. 2014; Paudel and Baral 2015). This suggests that ART services need to adopt strategies to help FSWs develop a healthy self-perception in relation to their HIV diagnosis and cope psychologically.

Despite concerns about risk compensation after initiating ART, we instead found a form of risk compensation in that HIV-positive, seroconcordant couples were least likely to use condoms, despite risks of re-infection and drug resistance. More broadly, however, the pattern of higher levels of condom use with paying clients versus lower levels with non-paying partners is consistent with the existing literature on condom-use behaviors among FSWs (Pearson et al. 2011; Luchters et al. 2008; Venkatesh et al. 2010). This underscores the importance of retaining clients on ART treatment and maintaining viral suppression.

Lastly, our quantitative and qualitative data indicate preference of the DIC model compared to the government-led facility. Over two-thirds of study participants chose to register for HIV care and treatment services at a DIC, and after one year, a significant proportion completed their last drug refill visit at a DIC or at both a facility and a DIC. Qualitative interviews with DIC clients indicate that they also find the facilities, which are located near large FSW hotspots, easier to access, and that the providers were caring and understanding. FSWs also preferred the greater privacy that the DICs offered over health facilities because DICs are often not crowded. This finding is supported by other SOAR community pilot studies for FSWs in Tanzania (Tun et al. 2019) and other community-based ART, test and start studies, and systematic reviews in sub-Saharan Africa (Mountain et al. 2014; Dave et al. 2019; Govindasamy et al. 2014; Koenig et al. 2017; Mwai et al. 2013; Mukherjee et al. 2016). 


\section{LIMITATIONS}

First, the study did not have a control or comparison group. Some of the improvements in key ART and HIV-related outcomes in the DIC model or at endline, such as ART initiation and violence, may be due to selection bias between those who initiated ART at DIC and those who initiated ART at health facilities or by other ongoing interventions. However, our data showed that selection bias was not the case; participants accessing the two models were comparable in key characteristics. In addition, our qualitative interviews showed a consensus among FSW clients that the DIC model is preferred and meets their unique needs and desires. Second, due to staffing challenges at the DICs in Mangochi district, participants recruited early in the study were unable to initiate treatment through the DICs directly. Thus facility-based initiation was higher in Mangochi, compared to Blantyre. Third, our ART initiation and current use of ART were self-reported, which are prone to social desirability biases. Observed decreases in experiences of violence and depression may also be influenced by social desirability bias. However, we expect this type of bias to be similar between participants of the two modalities. Furthermore, the use of ODK handheld devices in collecting data would have reduced self-reporting bias. Fourth, our key adherence measure, VL, was extracted from clinic records. As comparatively few clients had received a VL test, and even fewer had test results recorded in their records, estimates of viral suppression must be interpreted with care. However, the results extracted from health records were consistent with clients' recall of $\mathrm{VL}$ testing when asked during the surveys. 


\section{CONCLUSION AND RECOMMENDATIONS}

Based on the main findings, we have the following conclusions and recommendations:

- The study findings indicate the need to improve HIV testing among FSWs in Malawi in order to bring HIV-positive FSWs to ART treatment as soon as possible. This is particularly important as sexual risk behavior is high with both paying and non-paying clients, and a high proportion of FSWs also have stable sex partners, while HIV disclosure is low.

- Malawi is close to achieving the second and third 90s. Linkages and retention are quite high under the test and start policy adopted by the government in 2016. Of the many innovations in ART service, the DIC model has been shown to improve ART initiation while maintaining comparable retention and adherence levels to government-run facilities. The finding brings additional evidence in supporting the UNAIDS's focus on strengthening community platforms, which is illustrated by UNAIDS's 90-90-90 and Fast-Track cities initiatives (UNAIDS 2014), and the Global HIV Prevention Coalition to accelerate access to combination HIV prevention in settings with high HIV incidence.

- Infrequent VL testing reported by participants, and data gaps for VL test results found in patient care files, calls for further investigation. VL data is critical in monitoring clients' response to treatment, especially under the test and start policy in which CD4 testing is omitted. Thus, given the increased HIV transmission risks among women who sell sex, additional work is needed to ensure that these women are receiving at least one $V L$ test per year and that $V L$ test results are adequately recorded in patient files. This challenge is compounded by frequent migration between facilities and districts and concomitant gaps in patient health records, therefore measures to further strengthen the national HIV health record system are likely needed.

- FSWs indicated a strong preference for several key aspects of the ART services via the DIC model. Specifically, they liked the non-stigmatized attitude from providers, the convenience and flexibility of drug pickups, and the confidentiality it provides, as well as the helpfulness and support of the peer navigators, which may prove key in fostering long term retention in care and viral suppression. Together with the positive impact of the DIC model on ART initiation and the feasibility of implementing this approach, we highly recommend the government to expand this model to meet the unique needs of FSWs.

- Given the substantive role of peer navigators as part of patients' social support network and their influential role in decisions about staying in care, financial and capacity building for peer navigators and other types of lay health workers as well as community-based service models are needed and will likely improve long-term engagement in care.

- Data showed a high prevalence of sexual violence and a decrease after one year. The continuation of LINKAGES GBV interventions, such as sex-worker empowerment, community mobilization to respond to violence, and referrals to GBV services, are critical and may have contributed to this effect. We recommend further monitoring of such GBV interventions among FSWs to measure this aspect. 
- We also recommend that strategies to reduce internalized HIV stigma be an integral part of HIV services. Such strategies include linkage to peer educators/supporters who understand their lifestyle, peer support groups, educating oneself/others about HIV, viewing HIV as a manageable condition, and controlled and pre-emptive HIV disclosure. These strategies can help patients with their self-perceptions in relation to their HIV diagnosis so that they can adopt a healthier self-perception and cope with a positive HIV diagnosis.

- Due to FSWs' mobility, we recommend the government increase availability of multi-month prescriptions to reduce missed appointments, especially for FSWs who are known to travel. In addition, this would reduce the frequency of clinic visits and therefore reduce the possibility of clients being identified by community members as having HIV.

- Communication and client transfer procedures between DICs and health facilities should be established to help unify client health records, eliminate data gaps, and facilitate client transfers between DICs and health facilities. Although patient data collected from the DICs are currently being manually entered into the national EMR system, connecting the DICs to the EMR system directly would likely provide substantial improvement in coordinating client transfers and reducing data gaps. Alternatively, implementing universal patient ID cards or highly secure biometric identification may also be suitable to this purpose, though care would have to be taken to protect FSW client identities due to their affiliation with a vulnerable and often persecuted population. Efforts to coordinate client tracking and tracing and to consolidate health record data will not only be more important as the network of DIC sites grows, but also has practical application in improving continuity of care among the greater population of PLHIV. 


\section{REFERENCES}

Bemelmans, M., et al. 2014. "Community-supported models of care for people on HIV treatment in sub-Saharan Africa,” Tropical Medicine \& International Health 19(8): 968-77. doi: 10.1111/tmi.12332

Dave, S., et al. 2019. "Which community-based HIV initiatives are effective in achieving UNAIDS 90-90-90 targets? A systematic review and meta-analysis of evidence (2007-2018)," PLoS One 14(7): e0219826. doi: 10.1371/ journal.pone.0219826

Govindasamy, D., et al. 2014. "Interventions to improve or facilitate linkage to or retention in pre-ART (HIV) care and initiation of ART in low- and middle-income settings-a systematic review," Journal of the International AIDS Society 17(1): 19032. doi: 10.7448/IAS.17.1.19032

Havlir, D.V., et al. 2019. "HIV testing and treatment with the use of a community health approach in rural Africa," New England Journal of Medicine 381(3): 219-229. doi: 10.1056/NEJMoa1809866

Kalichman, S.C., et al. 2009. "Measuring AIDS stigmas in people living with HIV/AIDS: the Internalized AIDSRelated Stigma Scale," AIDS Care 21(1): 87-93. doi: 10.1080/09540120802032627

Kerrigan, D., et al. 2017. "Project Shikamana: Baseline findings from a community empowerment-based combination HIV prevention trial among female sex workers in Iringa, Tanzania," Journal of Acquired Immune Deficiency Syndromes 74(Suppl 1): S60-S68. doi: 10.1097/QAI.0000000000001203

Koenig, S.P. et al. 2017. "Same-day HIV testing with initiation of antiretroviral therapy versus standard care for persons living with HIV: A randomized unblinded trial," PLoS Medicine 14(7): e1002357. doi: 10.1371/journal. pmed.1002357

Konate, I., et al. 2011. "Linking HIV prevention and care for community interventions among high-risk women in Burkina Faso-the ARNS 1222 'Yerelon' cohort," Journal of Acquired Immune Deficiency Syndromes 57(Suppl 1): S50-4. doi: 10.1097/QAl.0b013e3182207a3f

Lancaster, K.E., et al. 2016. "The HIV care continuum among female sex workers: A key population in Lilongwe, Malawi,” PLoS One 11(1): e0147662. doi: 10.1371/journal.pone.0147662

Luchters, S., et al. 2008. "Safer sexual behaviors after 12 months of antiretroviral treatment in Mombasa, Kenya: a prospective cohort," AIDS Patient Care STDs 22(7): 587-94. doi: 10.1089/apc.2007.0247

Ministry of Health and Social Welfare and National AIDS Control Programme (Tanzania). 2014. Consensus Estimates on Key Population Size and HIV Prevalence in Tanzania. Dar Es Salaam, Tanzania: Ministry of Health and Social Welfare and National AIDS Control Programme (Tanzania).

Ministry of Health and Social Welfare and National AIDS Control Programme (Tanzania). 2015. National Guidelines for the Management of HIV and AIDS. Dar Es Salaam, Tanzania: Ministry of Health and Social Welfare and National AIDS Control Programme (Tanzania).

Mountain, E. et al. 2014. "Antiretroviral therapy uptake, attrition, adherence and outcomes among HIV-infected female sex workers: a systematic review and meta-analysis," PLoS One 9(9): e105645.

Mukherjee, J.S. et al. 2016. "Community-based ART programs: Sustaining adherence and follow-up," Current HIV/ AIDS Reports 13(6): 359-366. doi: 10.1007/s11904-016-0335-7

Mwai, G.W., et al. 2013. "Role and outcomes of community health workers in HIV care in sub-Saharan Africa: a systematic review," Journal of the International AIDS Society 16(1): 18586. doi: 10.7448/IAS.16.1.18586

National Statistical Office. 2014. Malawi Biological and Behavioural Surveillance Survey: preliminary results. Zomba, Malawi: National Statistical Office.

National Statistical Office and ICF Macro. 2011. Malawi Demographic and Health Survey 2010. Zomba, Malawi and Bethesda, MD: National Statistical Office and ICF Macro. 
Paudel, V. and K.P. Baral. 2015. "Women living with HIV/AIDS (WLHA), battling stigma, discrimination and denial and the role of support groups as a coping strategy: a review of literature," Reproductive Health 12: 53 . doi: $10.1186 / \mathrm{s} 12978-015-0032-9$

Pearson, C.R., et al. 2011. "Change in sexual activity 12 months after ART initiation among HIV-positive Mozambicans," AIDS and Behavior 15(4): 778-787. doi: 10.1007/s10461-010-9852-3

Research to Prevention (R2P). 2013. "Strategic assessment to define a comprehensive response to HIV in Iringa, Tanzania. Female sex workers," Research Brief. Baltimore, MD: Johns Hopkins University. Available from: http:// www.jhsph.edu/research/centers-and-institutes/research-to-prevention/publications/iringa/Iringa-FSW-brief-final. pdf.

Rosen, S. and M.P. Fox. 2011. "Retention in HIV care between testing and treatment in sub-Saharan Africa: a systematic review," PLoS Medicine 8: e1001056. doi: 10.1371/journal.pmed.1001056

Sabapathy, K., et al. 2017. "Predictors of timely linkage-to-ART within universal test and treat in the HPTN 071 (PopART) trial in Zambia and South Africa: findings from a nested case-control study," Journal of the International AIDS Society 20(4): e25037. doi: 10.1002/jia2.25037.

Scorgie, F., et al. 2013. “'We are despised in the hospitals': sex workers' experiences of accessing health care in four African countries," Culture, Health \& Sexuality 15(4): 450-465. doi: 10.1080/13691058.2012.763187

Tomori, C., et al. 2014. "Barriers and facilitators of retention in HIV care and treatment services in Iringa, Tanzania: the importance of socioeconomic and sociocultural factors," AIDS Care 26(7): 907-913. doi: 10.1080/09540121.2013.861574

Tun, W., et al. 2019. "Community-based antiretroviral therapy (ART) delivery for female sex workers in Tanzania: 6-month ART initiation and adherence," AIDS and Behavior 23(Suppl 2): 142-152. doi: 10.1007/s10461-01902549-x

Udedi, M. et al. 2018. “Integrating depression management into HIV primary care in central Malawi: the implementation of a pilot capacity building program," BMC Health Services Research 18: 593. https://doi. org/10.1186/s12913-018-3388-z

UNAIDS. 2014. “UNAIDS fast-track, ending the AIDS epidemic by 2030.” Geneva: UNAIDS. Accessed 24 May 2017 at: http://www.unaids.org/en/resources/campaigns/World-AIDS-Day-Report-2014.

UNAIDS. 2015. UNAIDS Country Progress Report. Geneva: UNAIDS.

Venkatesh, K.K. et al. 2010. "Decreased sexual risk behavior in the era of HAART among HIV-infected urban and rural South Africans attending primary care clinics," AIDS 24(17): 2687-2696. doi: 10.1097/ QAD.0b013e32833e78d4

Vu, L., et al. 2019. "Community-based antiretroviral therapy (ART) delivery for female sex workers in Tanzania: intervention model and baseline findings," AIDS Care 32(6): 729-734. doi: 10.1080/09540121.2019.1640846

World Health Organization. 2014. Consolidated Guidelines on HIV Prevention, Diagnosis, Treatment and Care for Key Populations. Geneva: World Health Organization. 
Project SOAR

Population Council 4301 Connecticut Ave, NW,

Suite 280

Washington, D.C. 20008 USA

Tel: +1 2022379400

Fax: +1 2022378410

Ideas. Evidence. Impact.

projsoar.org 